\title{
Coplanar Waveguide Slot-Coupled Patch Antenna Electronic Scanning Array for On-The-Move SATCOM
}

\author{
Steven D. Keller", Russell W. Harris, Khamsouk Kingkeo \\ U.S. Army Research Laboratory, Adelphi, MD 20783, USA \\ Email: steven.keller4@us.army.mil
}

\section{Introduction}

The ability of the warfighter to maintain a functional communications link with sources beyond-line-of-sight (BLOS) while actively moving about a battlefield that is comprised of variable terrain is a major objective for current Army communications system research. By utilizing the broad network coverage provided by future Army satellite communication systems, it may be possible to accomplish this objective with lightweight, low visual signature satellite communications on-the-move (SOTM) devices.

As part of the Affordable Low Profile SOTM (ALPS) Army Technical Objective (ATO), a 16-element $\mathrm{K}_{\mathrm{a}}$-band patch antenna electronic scanning array (ESA) with integrated MEMS phase shifters for beam steering has been designed to demonstrate a compact, efficient wafer-scale uplink mechanism for compatibility with future Army satellite communication systems. The array includes a unique coplanar waveguide (CPW) slot coupled patch antenna design, first pioneered in [1] and adapted for the present Army applications in [2] and [3] in order to minimize the overall system weight and fabrication complexity without sacrificing performance.

\section{Patch Antenna Array Design}

The $\mathrm{K}_{\mathrm{a}}$-band CPW slot-coupled patch antenna discussed in [2], shown in Figure 1 and originally designed for incorporation into a silicon-based wafer scale demonstrator array, was modified to operate on 20 mil thick RT/Duroid 6010 substrate at $30 \mathrm{GHz}$ and to meet minimum line and gap width fabrication specifications. The updated patch antenna dimensions are $1.27 \times 1.27 \mathrm{~mm}$, with a CPW feedline center conductor width, $\mathrm{S}_{\text {patch }}$, of $300 \mu \mathrm{m}$ and slot width, $\mathrm{w}_{\text {patch }}$, of $140 \mu \mathrm{m}$. A quarter wavelength tuning stub incorporated at the aperture to optimize the input impedance has a length of $750 \mu \mathrm{m}$ and width of 60 $\mu \mathrm{m}(20 \%$ of the feedline center conductor width).

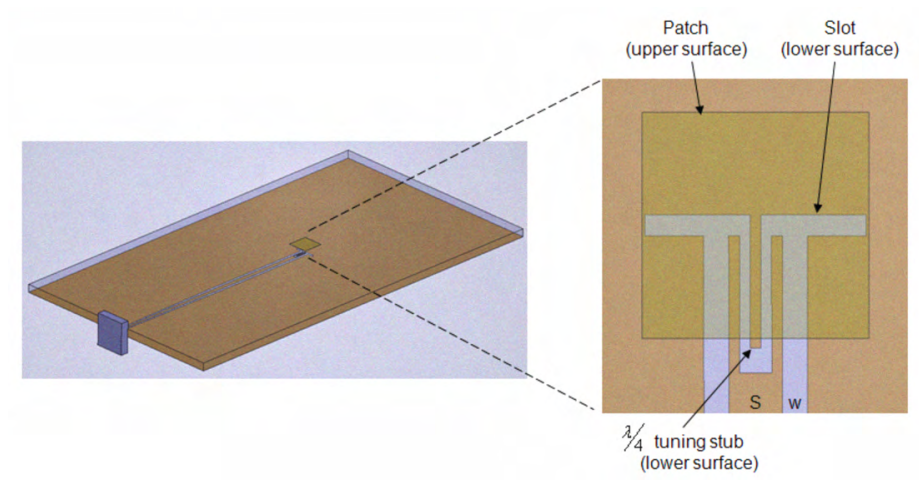

Figure 1. $\mathrm{K}_{\mathrm{a}}$-band CPW slot-coupled patch antenna design. 
The antenna was simulated in Ansoft HFSS to ensure an acceptable bandwidth and center frequency for the final ESA. The return loss plot shown in Figure 2 indicates an excellent resonance at $\sim 30 \mathrm{GHz}$ with a $10 \mathrm{~dB}$ return loss bandwidth of $\sim 1.65 \mathrm{GHz}(5.5$ $\%$ ), from $29.13-30.78 \mathrm{GHz}$. The simulation results correlate well with the measured data and accurately predict both the center frequency and bandwidth. The full sixteenelement array should yield a comparable center frequency and bandwidth, though subtle differences are expected due to the probable increase in insertion loss and substrate-topatch size ratio.

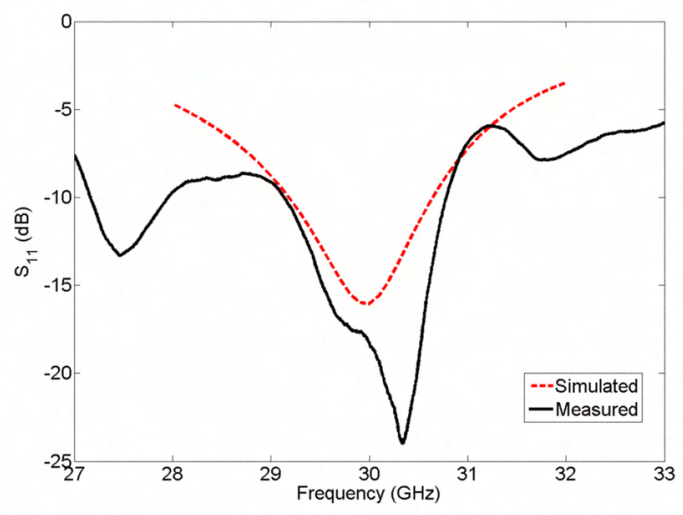

Figure 2. Simulated and measured return loss for CPW slot-coupled patch antenna.

With an optimized patch antenna to serve as the array element, the CPW feedline artwork for the 1x16 planar array was then developed for integration with this design. Since beam steering is controlled by MEMS phase shifters, each element in the array is driven with equal power. In order to produce equal power division between the antennas, a Wilkinson power divider strategy was employed, as shown in Figure 3. A simulation of this design, detailed further in [3], indicated that the power divider insertion loss varied from 0.4 to $0.8 \mathrm{~dB}$ for the majority of the frequency range and was acceptable for this application.

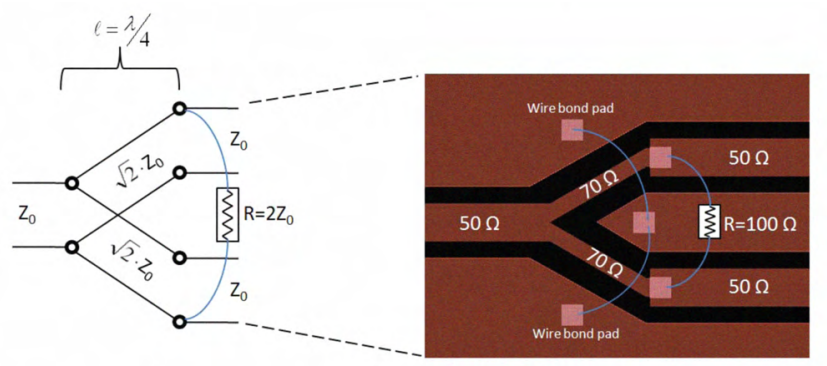

(a)

(b)

Figure 3. Wilkinson power divider design. (a) Transmission line circuit of Wilkinson power divider (adapted from [4]). (b) CPW application of Wilkinson power divider. 


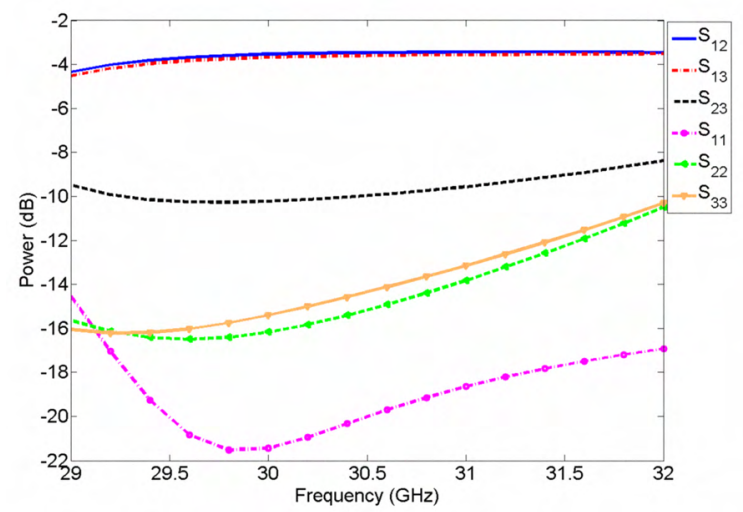

Figure 4. Simulation results for $\mathrm{K}_{\mathrm{a}}$-band Wilkinson power divider.

\section{MEMS Phase Shifter Integration}

For the beam steering mechanism of the ESA, a custom MEMS phase shifter device designed by Raytheon Co. was integrated into the array feedline network. The footprint of this device incorporated into the ESA feedline network is shown in Figure 5. Since the input/output ports and DC control ports for the phase shifters were offset by $\sim 10-15$ mil from the bottom of the device, a wire bond length of at least $16-20$ mil would be required if the devices were placed flush with the CPW feedline layer and the quality of the input/output port impedance match to the CPW feedlines would be significantly reduced. Thus, two 10 mil thick layers of RT/Duroid 6010 were bonded together to form the necessary 20 mil thick substrate, with rectangular holes cut out of the bottom layer to accommodate the phase shifter footprint. By placing the phase shifters in these $10 \mathrm{mil}$ deep slots, the vertical offset between the CPW feedlines and the phase shifter input/output ports was reduced to $0-5 \mathrm{mil}$. This resulted in a maximum wire bond length of $\sim 6 \mathrm{mil}$ and ensured that the wire bonds would minimally affect the port impedance match.

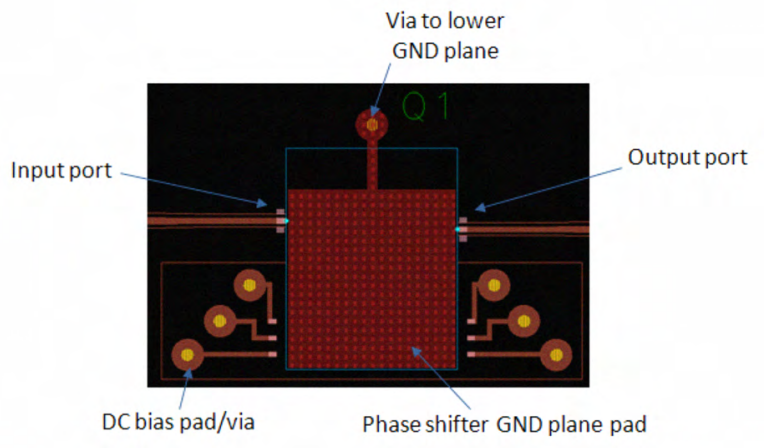

Figure 5. MEMS phase shifter footprint in ESA feedline layout.

The full $4 \times 4$ ", 16-element antenna array layout and the fabricated prototype prior to phase shifter integration are shown in Figure 6. In order to control the phase delay through each phase shifter, a bias voltage of $35-40 \mathrm{~V}$ was applied to the DC bias pads of each unit. The devices were designed using a binary phase shift scheme, with pads $1-4$ (upper and middle pads) producing $22.5^{\circ}, 45^{\circ}, 90^{\circ}$, and $180^{\circ}$ phase delay, respectively. The two bottom pads serve as a ground reference. A control board comprised of a 
programmable microcontroller, high voltage Darlington transistor array driver (ULN2003A) and signal control circuitry was designed to bias the phase shifters. In order to prevent damage to the phase shifters, a soft start of $\sim 4 \mathrm{~V} / \mathrm{ms}$ was produced by tying the outputs to an $\mathrm{R} / \mathrm{C}$ network with a $10 \mathrm{k} \Omega$ resistor connected to $+35 \mathrm{~V}$ and grounded through a $1 \mu \mathrm{F}$ capacitor. Beam steering was controlled by applying a variety of progressive phase shift commands to the microcontroller via a USB connection to a host computer.

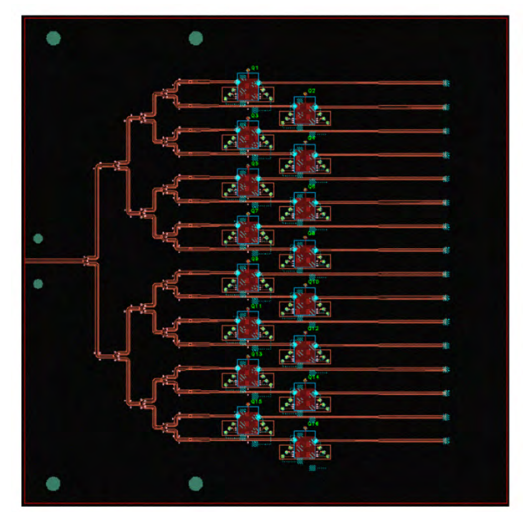

Figure 6. 16-element $\mathrm{K}_{\mathrm{a}}$-band patch antenna ESA layout.

\section{Conclusion}

The design of a $\mathrm{K}_{\mathrm{a}}$-band coplanar waveguide slot-coupled patch antenna ESA with integrated MEMS phase shifters has been described above. The incorporation of MEMS phase shifters into the ESA design results in a compact, efficient uplink mechanism for a future Army satellite communication system. A control board for biasing the phase shifters and initiating beam steering will be incorporated into the final array. The details of this design and the measured beam steering results of the fully-fabricated demonstrator array will be presented at the 2009 IEEE Antennas and Propagation Society Conference.

\section{Acknowledgements}

The authors would like to thank Raytheon Co. for providing the MEMS phase shifters incorporated into this antenna array. Specifically, we thank Brandon Pillans (Raytheon Co.), for providing data and technical support for these devices throughout the design process.

\section{References}

[1] K. Hettak, G. Delisle and M. Boulmalf, "A novel integrated antenna for millimeter wave personal communications systems", IEEE Transactions on Antennas and Propagation, vol. 46, no. 11, pp. 1757-1758, November 1998.

[2] S. D. Keller, "Coplanar waveguide slot-coupled $\mathrm{K}_{\mathrm{a}}$-band patch antenna for integration with wafer-scale beam-steering MEMS control board", Applied Computational Electromagnetics Society Journal, vol. 23, no. 2, June 2008.

[3] S. D. Keller, " $K_{a}$-band patch antenna array with integrated MEMS phase shifters for satellite communications on-the-move uplink mechanism", USNC/URSI 2009 National Radio Science Meeting Conf. Proc., January 2009.

[4] D. Pozar, Microwave engineering, pp. 318-323, John Wiley \& Sons, 3rd edition, 2005. 